\title{
Analysis of Gedi Leaf (Abelmoschus Manihot L.) as Functional Drinking Tea
}

\author{
Ummu Aimanah \\ Sekolah Tinggi Penyuluhan Pertanian \\ South Sulawesi, Indonesia
}

\author{
Mulyati A. M. \\ Sekolah Tinggi Penyuluhan Pertanian \\ South Sulawesi, Indonesia
}

\author{
Ahmad Gussasi \\ Sekolah Tinggi Penyuluhan Pertanian \\ South Sulawesi, Indonesia
}

\begin{abstract}
Gedi leaves contain many flavonoid compounds that are used in healthcare. This paper will discuss how Gedi leaf can be processed as a functional, healthy tea drink. There are two objectives that to be addressed in this article. The first objective is to determine the bioactive compounds in the Gedi leaves such as flavonoids, vitamin $\mathrm{A}$, vitamin $\mathrm{C}$, fibre content, $\mathrm{pH}$ and water content. Secondly, it is to test the organoleptic beverage of Gedi leaves regarding flavour and colour. The results showed that bioactive components of the Gedi leaves tea have better water and fibre level for P1 test namely 11.893 and 14.7. Both were not significantly different for $t$-test. The levels of vitamin $C$ and vitamin A showed physical change. For hedonic test, panellists revealed that they like both colour and taste of the Gedi leaves tea.
\end{abstract}

Keywords: Gedi leaf; flavanoid; tea

\section{INTRODUCTION}

Tea is a famous drink worldwide and consumed by most adults, In average, adults consume no less than a few $120 \mathrm{ml}$ each day tea. Tea is also one of the most popular drink products eaten by many the people of Indonesia and the world because the tea has a distinctive taste and aroma. [1]

Tea becomes one of regular drink that most people have in everyday life. Nowadays, tea has been made from several sources such as Moringa leaves, brown leaves, and leaves of avocado. Several research showed that tea has many benefits and one of them is a remedy to eliminate depression [2], [3]. However, some foods and drinks have been produced without any consideration to their benefits and nutrition. Moreover, natural sources were not many used as food ingredients that have high nutrition.

Gedi leaf is one of the plants that has rich nutrition and benefits [4], [5]. The gedy plants (Abelmoschus manihot) belong to the Malvaceae tribe, with plant height about $1.2-1.8$ $\mathrm{m}$. Many researchers produced that gedi contains quercetin-3o-robinobiosid, hyperin, isoquercetin, gossipetin-8-oglucuronide, and myricetin. Gedy leaves have various health benefits such as preventing ovariectomy-induced femoral osteopenia, improving glomerular screening function, and reducing kidney tissue damage. It also contains many flavonoid compounds that one of its properties is to lower the risk of cardiovascular diseases such as heart disease [6]. This paper will discuss how Gedi leaf can be processed as a functional, healthy drinking tea.
There are two objectives that to be addressed in this paper. The first objective is to determine the bioactive compounds in the Gedi leaf such as flavonoids, vitamin A, vitamin C, fibre content, $\mathrm{pH}$ and water content. Secondly, it is to test the organoleptic beverage of gedi leaves regarding flavour and colour. There are several kinds of tea processing which had been considered in the test. First, the tea which is produced without using fermentation, for example, green tea. The others were processed with fully fermented such as Oolong and black teas. Moreover, the hedonic test has also be done in this research. It is a test performed by a person and some panellists that aim to determine the level of likes and dislikes [7].

\section{RESEARCH METHOD}

Implementation of the research activities carried out for three months in the laboratory of food science. The tools used in the implementation of this study were test tools of vitamin A and Vitamin $\mathrm{C}$, flavonoids, fibre content, water content and $\mathrm{pH}$, blender, filter, basin, pots, container, oven, and packaging sets. The materials used are the Gedi leaves. This research was conducted by two factorial randomized design group P1 and $\mathrm{P} 2$. P1 is a fermented tea from Gedi leaves, and P2 is a Gedi unfermented tea. The tests were conducted with three replications. Organoleptic test which is a test to know the preference level of the flavour and colour were carried out after the tea was brewed. Parameters are A1 (dry Gedi leaves powder 2 grams $+100 \mathrm{ml}$ water), A2 ( dry Gedi leaves powder 4 grams + water $100 \mathrm{ml}$ ), and A3 (dry Gedi leaves powder 6 grams + $100 \mathrm{ml}$ water). Analysis of water content was done by heating [8]. Analysis of flavonoids content was using spectrophotometry. Finally, analysis of Vitamin C and vitamin A used Iodine titration method [9].

\section{RESULTS AND DISCUSSION}

The results of water content in tea made from Gedi leaves for both fermented and not fermented were shown in figure 1. Analysis of variance for the standard error of 0.06 was less than 0.1 , so it can be expressed as not significantly different. 


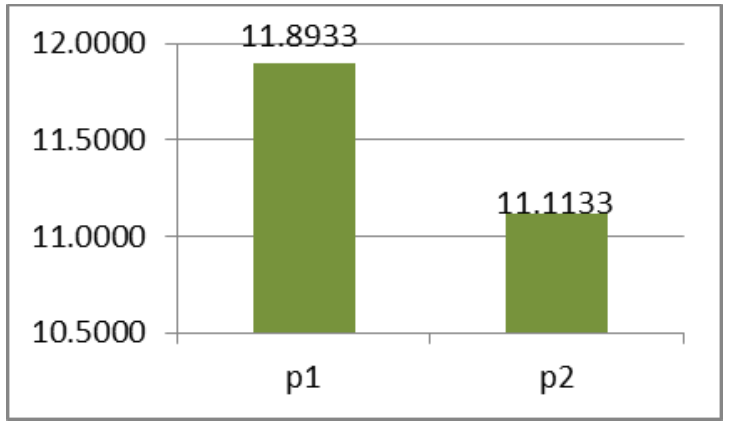

Fig. 1. Diagram of the moisture content of fermented Gedi tea (P1) and not fermented Gedi tea(P2).

The results obtained (P1) for the fermentation of the leaves higher at 11.8933 compared to the tea leaf (P2) which is not fermented. Vitamin $\mathrm{C}$ in the Gedi tea leaves showed results of 0.000 which are less than $<0.1$. It means that it was not significantly different. The results can be seen in Figure 2 below:

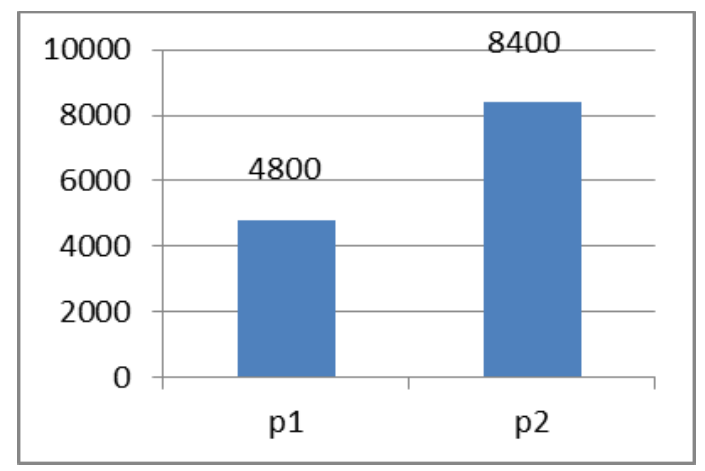

Fig. 2. Results of Vitamin C in fermented Gedi tea (P1) and not fermented Gedi tea(P2).

It can be seen from the figure that vitamin $\mathrm{C}$ level in $\mathrm{P} 2$ samples is 8400 and $\mathrm{P} 1$ are 4800 . The content of vitamin C was mostly broken during processing time. These changes are caused by the physical changes and reshuffle enzymatic oxidation.

The fiber content in the fermented Gedi leaves tea P1, and $\mathrm{P} 2$ which were derived from variance analysis obtained 0.02 $<0.1$ and can be seen in figure 3

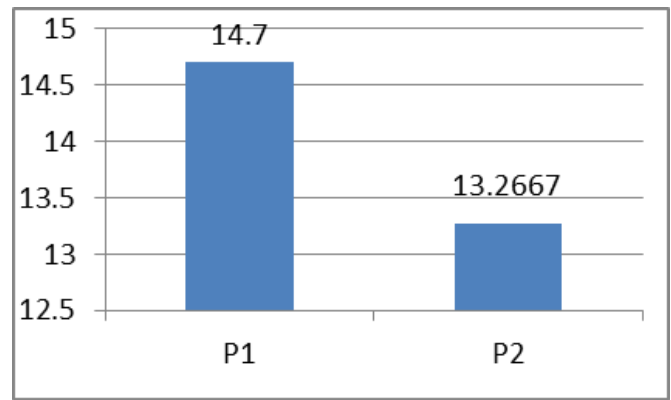

Fig. 3. Results of the fiber content in the fermented Gedi leaves tea P1 and not fermented Gedi tea P2
It can be seen that fibre levels in the Gedi tea $\mathrm{P} 1$ and $\mathrm{P} 2$ are 14.7 and 13.2667 respectively. The fibre content in the tea is insoluble in water.

Vitamin A, in this case, Carotene on fermented Gedi leaves tea P1 and unfermented P2 from analysis of variance obtained significantly different results $0.80>0.1$. The results can be seen in Figure 4.

What vitamin A in the Gedi leaves for the fermentation P1 is 8.5966, and unfermented P2 is 6.6044. It is because the vitamin A content in the Gedi leaf inside a carotene plant cell is found in its parts separate from the chloroplasts called chromoplast carotene [9].

Beta-carotene may act as antioxidants, which are important in the formation of vitamin A, for the growth of epithelial cells. Spectrophotometric technique can make the content of betacarotene in the material.

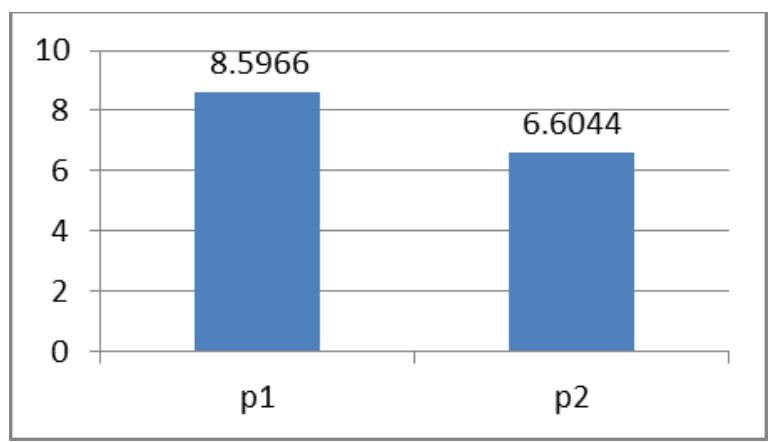

Fig. 4 Results of Vitamin A in fermented Gedi tea P1 and unfermented Gedi tea P2

\section{A Total Flavonoids test}

Flavonoids are a class of phenolic antioxidants. According to [10], the phenol is one of the plants' chemical components that have enormous benefits for the plants itself. This is consistent with [11] statement that by the phenol test the younger the leaves, the higher flavonoid levels. The results of linear regression for the standard curve on tea leaves Gedi are namely:

$$
\mathrm{y}=0,0501 \mathrm{x}-0.2087
$$

Absorbance readings on the tea leaves for both fermented Gedi (P1) and not fermented Gedi (P2) is inserted into a linear regression to obtain the concentration of flavonoids.

\section{$B$ The Hedonic test for colour and flavour}

The hedonic test which was conducted by several panellists to know the preference level in terms of colour and flavour. It was found that for colour preference level, the A1 group was selected as the highest number of very like criteria. Panelists preferred the tea colour with 2 grams Gedi leaves and added with $100 \mathrm{ml}$ water. On the other hand, A3 treatment is mostly not preferred because of its bright colour. The bright colour in A3 treatment is obtained as the number of leaves is too much compared to the others. In term of flavour, the taste of tea with 4 gram of leaves in treatment $\mathrm{A} 2$ is mostly favoured by 
panellists, while the taste of A3 was also not preferred by the panellists.

\section{CONCLUSION}

Both tests which were conducted on the tea made from Gedi leaves showed that tea could be served as a functional, healthy drink. The bioactive components of the tea are high, and there were not significant differences between fermented and unfermented tea. Moreover, the panellists in hedonic test showed that they like both colour and taste of the tea in a proportional amount of Gedi leaves and water.

\section{REFERENCES}

[1] D. Jefferies et al., "Water footprint and life cycle assessment as approaches to assess potential impacts of products on water consumption. Key learning points from pilot studies on tea and margarine," J. Clean. Prod., vol. 33, pp. 155-166, 2012.

[2] N. M. Pham et al., "Green tea and coffee consumption is inversely associated with depressive symptoms in a Japanese working population," Public Health Nutr., vol. 17, no. 3, pp. 625-633, 2014.

[3] J. Hintikka et al., "Daily tea drinking is associated with a low level of depressive symptoms in the Finnish general population," Eur. J. Epidemiol., vol. 20, no. 4, pp. 359-363, 2005.

[4] M. Liu, Q. Jiang, J. Hao, and L. Zhou, "Protective effect of total flavones of Abelmoschus manihot L. Medic against poststroke depression injury in mice and its action mechanism," Anat. Rec., vol. 292, no. 3, pp. 412-422, 2009.

[5] G. Ai, Q. Liu, W. Hua, Z. Huang, and D. Wang, "Hepatoprotective evaluation of the total flavonoids extracted from flowers of Abelmoschus manihot (L.) Medic: in vitro and in vivo studies," $J$. Ethnopharmacol., vol. 146, no. 3, pp. 794-802, 2013.

[6] C.-Z. Wang, S. R. Mehendale, T. Calway, and C.-S. Yuan, "Botanical flavonoids on coronary heart disease," Am. J. Chin. Med., vol. 39, no. 4, pp. 661-671, 2011.

[7] H. T. Lawless and H. Heymann, Sensory evaluation of food: principles and practices. Springer Science \& Business Media, 2010.

[8] P. Feldsine, C. Abeyta, and W. H. Andrews, "AOAC International methods committee guidelines for validation of qualitative and quantitative food microbiological official methods of analysis," $J$. AOAC Int., vol. 85, no. 5, pp. 1187-1200, 2002.

[9] R. R. Eitenmiller, W. O. Landen Jr, and L. Ye, Vitamin analysis for the health and food sciences. CRC press, 2016.

[10] J. A. Rothwell et al., "Phenol-Explorer 3.0: a major update of the Phenol-Explorer database to incorporate data on the effects of food processing on polyphenol content," Database, vol. 2013, p. bat070, 2013.

[11] S. E.-S. Saffan and A. M. D. El-Mousallamy, "Allelopathic effect of Acacia raddiana leaf extract on the phytochemical contents of germinated Lupinus termis Seeds," J. Appl. Sci. Res., vol. 4, no. 3, pp. 270-277, 2008. 